\title{
Is there still a place for noninvasive ventilation in acute hypoxemic respiratory failure?
}

\author{
Audrey De Jong ${ }^{1 *}$, Gonzalo Hernandez ${ }^{2}$ and Davide Chiumello 3,4
}

๑ 2018 Springer-Verlag GmbH Germany, part of Springer Nature and ESICM

There is strong evidence for the use of noninvasive ventilation (NIV) rather than standard oxygen alone to reduce the reintubation rate in several forms of acute respiratory failure (ARF): acute exacerbation of chronic obstructive pulmonary disease (COPD), cardiogenic pulmonary edema, and hypoxemia post-abdominal surgery $[1,2]$. The debate lies in the fact that the majority of patients with acute hypoxemic respiratory failure do not fall into these buckets. NIV (with either positive end-expiratory pressure [PEEP] or continuous positive airway pressure) was until recently considered the gold standard of initial oxygenation strategies. A new method of oxygenation was launched in the 2010s, high-flow nasal cannula oxygen (HFNC), providing a high flow of humidified oxygen, with a low level of PEEP (from 2 to $6 \mathrm{~cm} \mathrm{H}_{2} \mathrm{O}$, depending on the flow rate and the opening or closing of the mouth). The FLORALI trial [3] reported in 2015 that NIV was independently associated with increased mortality compared to HFNC in patients with acute hypoxemic ARF. Similar results were observed in the LUNG SAFE multicenter observational study by Bellani et al. [4]. However, in the large cohort study by Demoule et al. [5] investigating trends in NIV use over time, NIV failure in acute hypoxemic ARF was no longer associated with mortality in 2010 and 2011, contrary to the findings of 1997 and 2002.

In the specific population of ARF immunocompromised patients, a post hoc analysis of the FLORALI trial

\footnotetext{
*Correspondence: audreydejong@hotmail.fr

1 PhyMedExp, University of Montpellier, INSERM U1046, CNRS, UMR 9214 Anesthesia and Critical Care Department B, Saint Eloi Teaching Hospital, Centre Hospitalier Universitaire Montpellier, 34295 Montpellier Cedex 5, France

Full author information is available at the end of the article
}

confirmed the findings of the initial study, i.e., a decrease in the mortality rate using HFNC compared to NIV [6]. However, these results differed from those of a dedicated randomized controlled trial (RCT) [7] and a large prospective multinational cohort that reported no benefit and no harm from NIV in immunocompromised patients [8].

Some explanations can be proffered when analyzing the better outcome with HFNC compared to NIV. Potential beneficial effects of HFNC include administration of warm and humidified oxygen, providing of a moderate level of PEEP, allowing less inspiratory effort, and improved lung volume and compliance. Interface selection may be a major determinant of NIV failure [9]. NIV with a helmet, compared with a traditional face mask, was associated with reduced hospital mortality and intubation requirement in a single-center randomized study [10]. Regardless of the interface used, NIV cannot avoid high tidal volumes when being delivered to hypoxemic patients with high respiratory drives, and therefore, possible ventilator-induced lung injury and worsening of respiratory status may occur [11]. It is worth noting that high tidal volumes might also occur with HFNC. Table 1 presents the arguments for consideration in favor and against NIV use in hypoxemic ARF patients. In the case of associated decompensation of COPD, fluid overload, or chest trauma [12], or in a postoperative setting following abdominal surgery [1], NIV could be attempted. In the case of rapid clinical and biological improvement, NIV may be continued until resolution of symptoms. The aim should be rapid (in $1 \mathrm{~h}$ ) improvement in clinical (signs of respiratory distress) and biological (hypercapnia and hypoxia) symptoms. Otherwise, intubation for invasive mechanical ventilation must be performed. Dyspnea 
Table 1 Benefit-risk ratio assessment in favor or against NIV use in hypoxemic ARF patients

Indications for NIV use
Acute exacerbation of COPD
Acute cardiogenic pulmonary edema
Hypoxemia post-abdominal surgery
Chest trauma
Preoxygenation before intubation
Against NIV use
(Late or moderate-severe) ARDS
High tidal volumes during the NIV session
Leaks during the NIV session despite changes of interface
Lack of patient adherence
Dyspnea during NIV sessions
Impossibility of close monitoring
Absence of rapid clinical improvement (signs of respiratory distress
including elevated respiratory rate) and gas exchange improvement
after 1 h of NIV session

$A R F$ acute respiratory failure, NIV noninvasive ventilation, COPD chronic obstructive pulmonary disease, ARDS acute respiratory distress syndrome

occurrence during the NIV session is associated with NIV failure when present [13], and may be an important variable to assess when deciding whether to perform an intubation procedure. If intubation is deemed appropriate, although apneic oxygenation is the most commonly investigated respiratory support technique for critically ill patients undergoing intubation, NIV is still the reference method for preoxygenation of patients with severe hypoxemia [14]. Compared to traditional preoxygenation with an oxygen facial mask during the intubation procedure, NIV for preoxygenation of patients with severe hypoxemic ARF is associated with less hypoxemia [14]. Indeed, combining pressure support with PEEP limits alveolar collapse and atelectasis formation, responsible for hypoventilation and low perfusion ventilation ratio. Using HFNC combined with NIV may have advantages over conventional NIV alone for preoxygenation before intubation procedures in hypoxemic patients in the intensive care unit (ICU). The technique of preoxygenation combining NIV and HFNC-combining the concepts of prevention of alveolar derecruitment and apneic oxygenation, respectively-was recently assessed [15]. Compared with NIV alone, when the combination of NIV and HFNC (OPTINIV method) was used, the lowest saturation during the intubation procedure was significantly increased.

The literature is therefore inconclusive in terms of harm or benefit from NIV in hypoxemic ARF patients. More than the use of NIV, it is the need for invasive mechanical ventilation after NIV failure that is associated with mortality [5]. However, mortality associated with invasive mechanical ventilation has decreased significantly over the last two decades. Being intubated for mechanical ventilation is not the big bad wolf anymore. The recent evidence is in favor of not using NIV in ARF patients (in particular in the case of ARDS), except for those with acute exacerbation of COPD or acute cardiogenic pulmonary edema, or following abdominal surgery or chest trauma. Outside of the peri-intubation period, the use of NIV should best be avoided-at least outside of expert hands and without close monitoring including respiratory rate and prompt intubation in the case of non-improvement.

Whatever the method of oxygenation used, the dangers in delaying intubation must be underscored. Indeed, when intubation is delayed in ICU patients, mortality is consistently increased. One of the first studies showing the risks of a delayed intubation was that of Esteban et al. [16]. The interval between the onset of respiratory failure and reintubation was significantly longer in the NIV group than in the standardtherapy group. Similar results were found with the use of HFNC [17]. Kang et al. [17] showed that failure of HFNC might cause delayed intubation and worse clinical outcomes in patients with respiratory failure. Inappropriate use of one of the available oxygen devices (standard oxygen, HFNC, or NIV) might delay intubation and lead to adverse outcomes.

One strategy may not fit all. Individualized patient management would seem to be critical, taking into account the complexity of a single patient. Oxygenation is not the only treatment for hypoxemic ARF. The cause of ARF must be identified and cured, and then the respiratory state of the patient will be able to improve.

\section{Author details \\ 1 PhyMedExp, University of Montpellier, INSERM U1046, CNRS, UMR 9214, Anesthesia and Critical Care Department B, Saint Eloi Teaching Hospital, Centre Hospitalier Universitaire Montpellier, 34295 Montpellier Cedex 5, France. ${ }^{2}$ Critical Care Medicine, University Hospital Virgen de la Salud, Toledo, Spain. ${ }^{3}$ Centro di Ricerca Coordinata di Insufficienza Respiratoria, Università degli Studi di Milano, Milan, Italy. ${ }^{4}$ Dipartimento di Emergenza-Urgenza, SC Anestesia e Rianimazione, ASST Santi Paolo e Carlo, Milan, Italy.}

\section{Compliance with ethical standards}

\section{Conflicts of interest}

A. De Jong reports personal fees from Baxter and Medtronic-Covidien, and travel reimbursement from Fresenius Kabi, MSD France, Astellas, Pfizer, and Fisher \& Paykel. G. Hernandez reports personal fees and travel expenses from Fisher Paykel. D. Chiumello has no conflict of interest.

Received: 8 September 2018 Accepted: 11 October 2018

Published online: 23 October 2018 


\section{References}

1. Jaber $S$, Lescot T, Futier E, Paugam-Burtz C, Seguin P, Ferrandiere M, Lasocki S, Mimoz O, Hengy B, Sannini A, Pottecher J, Abback PS, Riu B, Belafia F, Constantin JM, Masseret E, Beaussier M, Verzilli D, De Jong A, Chanques G, Brochard L, Molinari N (2016) Effect of noninvasive ventilation on tracheal reintubation among patients with hypoxemic respiratory failure following abdominal surgery: a randomized clinical trial. JAMA 315:1345-1353

2. Squadrone V, Coha M, Cerutti E, Schellino MM, Biolino P, Occella P, Belloni G, Vilianis G, Fiore G, Cavallo F, Ranieri VM (2005) Continuous positive airway pressure for treatment of postoperative hypoxemia: a randomized controlled trial. JAMA 293:589-595

3. Frat JP, Thille AW, Mercat A, Girault C, Ragot S, Perbet S, Prat G, Boulain T, Morawiec E, Cottereau A, Devaquet J, Nseir S, Razazi K, Mira JP, Argaud L, Chakarian JC, Ricard JD, Wittebole X, Chevalier S, Herbland A, Fartoukh M, Constantin JM, Tonnelier JM, Pierrot M, Mathonnet A, Beduneau G, Deletage-Metreau C, Richard JC, Brochard L, Robert R (2015) High-flow oxygen through nasal cannula in acute hypoxemic respiratory failure. $\mathrm{N}$ Engl J Med 372:2185-2196

4. Bellani G, Laffey JG, Pham T, Madotto F, Fan E, Brochard L, Esteban A, Gattinoni L, Bumbasirevic V, Piquilloud L, van Haren F, Larsson A, McAuley DF, Bauer PR, Arabi YM, Ranieri M, Antonelli M, Rubenfeld GD, Thompson BT, Wrigge H, Slutsky AS, Pesenti A (2017) Noninvasive ventilation of patients with acute respiratory distress syndrome. Insights from the LUNG SAFE Study. Am J Respir Crit Care Med 195:67-77

5. Demoule A, Chevret S, Carlucci A, Kouatchet A, Jaber S, Meziani F, Schmidt M, Schnell D, Clergue C, Aboab J, Rabbat A, Eon B, Guerin C, Georges H, Zuber B, Dellamonica J, Das V, Cousson J, Perez D, Brochard L, Azoulay E (2016) Changing use of noninvasive ventilation in critically ill patients: trends over 15 years in francophone countries. Intensive Care Med 42:82-92

6. Frat JP, Ragot S, Girault C, Perbet S, Prat G, Boulain T, Demoule A, Ricard JD, Coudroy R, Robert R, Mercat A, Brochard L, Thille AW (2016) Effect of non-invasive oxygenation strategies in immunocompromised patients with severe acute respiratory failure: a post hoc analysis of a randomised trial. Lancet Respir Med 4:646-652

7. Lemiale V, Mokart D, Resche-Rigon M, Pene F, Mayaux J, Faucher E, Nyunga M, Girault C, Perez P, Guitton C, Ekpe K, Kouatchet A, Theodose I, Benoit D, Canet E, Barbier F, Rabbat A, Bruneel F, Vincent F, Klouche K, Loay K, Mariotte E, Bouadma L, Moreau AS, Seguin A, Meert AP, Reignier J, Papazian L, Mehzari I, Cohen Y, Schenck M, Hamidfar R, Darmon M, Demoule A, Chevret S, Azoulay E (2015) Effect of noninvasive ventilation vs oxygen therapy on mortality among immunocompromised patients with acute respiratory failure: a randomized clinical trial. JAMA 314:1711-1719
8. Azoulay E, Pickkers P, Soares M, Perner A, Rello J, Bauer PR, van de Louw A, Hemelaar P, Lemiale V, Taccone FS, Martin Loeches I, Meyhoff TS, Salluh J, Schellongowski P, Rusinova K, Terzi N, Mehta S, Antonelli M, Kouatchet A, Barratt-Due A, Valkonen M, Landburg PP, Bruneel F, Bukan RB, Pene F, Metaxa V, Moreau AS, Souppart V, Burghi G, Girault C, Silva UVA, Montini L, Barbier F, Nielsen LB, Gaborit B, Mokart D, Chevret S (2017) Acute hypoxemic respiratory failure in immunocompromised patients: the Efraim multinational prospective cohort study. Intensive Care Med 43:1808-1819

9. Esquinas Rodriguez AM, Papadakos PJ, Carron M, Cosentini R, Chiumello D (2013) Clinical review: helmet and non-invasive mechanical ventilation in critically ill patients. Crit Care 17:223

10. Patel BK, Wolfe KS, PohIman AS, Hall JB, Kress JP (2016) Effect of noninvasive ventilation delivered by helmet vs face mask on the rate of endotracheal intubation in patients with acute respiratory distress syndrome: a randomized clinical trial. JAMA 315:2435-2441

11. Carteaux G, Millan-Guilarte T, De Prost N, Razazi K, Abid S, Thille AW, Schortgen F, Brochard L, Brun-Buisson C, Mekontso Dessap A (2016) Failure of noninvasive ventilation for de novo acute hypoxemic respiratory failure: role of tidal volume. Crit Care Med 44:282-290

12. Hernandez G, Fernandez R, Lopez-Reina P, Cuena R, Pedrosa A, Ortiz R, Hiradier $P$ (2010) Noninvasive ventilation reduces intubation in chest trauma-related hypoxemia: a randomized clinical trial. Chest 137:74-80

13. Dangers L, Montlahuc C, Kouatchet A, Jaber S, Meziani F, Perbet S, Similowski T, Resche-Rigon M, Azoulay E, Demoule A (2018) Dyspnoea in patients receiving noninvasive ventilation for acute respiratory failure: prevalence, risk factors and prognostic impact: a prospective observational study. Eur Respir J 9(2):52

14. Baillard C, Prat G, Jung B, Futier E, Lefrant JY, Vincent F, Hamdi A, Vicaut $E_{\text {, }}$ Jaber S (2018) Effect of preoxygenation using non-invasive ventilation before intubation on subsequent organ failures in hypoxaemic patients: a randomised clinical trial. Br J Anaesth 120:361-367

15. Jaber S, Monnin M, Girard M, Conseil M, Cisse M, Carr J, Mahul M, Delay JM, Belafia F, Chanques G, Molinari N, De Jong A (2016) Apnoeic oxygenation via high-flow nasal cannula oxygen combined with non-invasive ventilation preoxygenation for intubation in hypoxaemic patients in the intensive care unit: the single-centre, blinded, randomised controlled OPTINIV trial. Intensive Care Med 42:1877-1887

16. Esteban A, Frutos-Vivar F, Ferguson ND, Arabi Y, Apezteguia C, Gonzalez M, Epstein SK, Hill NS, Nava S, Soares MA, D’Empaire G, Alia I, Anzueto A (2004) Noninvasive positive-pressure ventilation for respiratory failure after extubation. N Engl J Med 350:2452-2460

17. Kang BJ, Koh Y, Lim CM, Huh JW, Baek S, Han M, Seo HS, Suh HJ, Seo GJ, Kim EY, Hong SB (2015) Failure of high-flow nasal cannula therapy may delay intubation and increase mortality. Intensive Care Med 41:623-632 